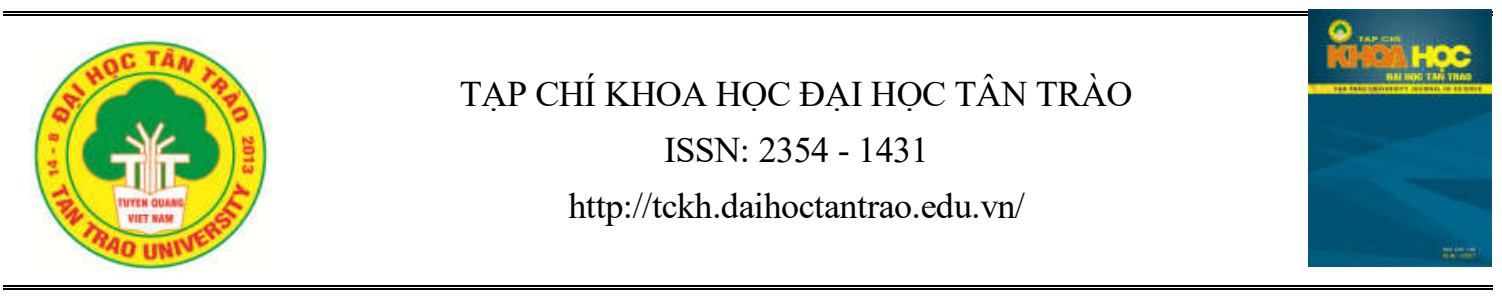

\title{
Xây dựng trường phổ thông thực hành liên cấp trong trường đại học - trao đổi từ thụ̣c tiễn của Trường Đại học Tân Trào, tỉnh Tuyên Quang
}

\author{
Nguyễn Đức Hạnh ${ }^{a}$, Nguyễn Bá Đức ${ }^{b}$ \\ ${ }^{a}$ Truò̀ng Đại hoc Đại Nam \\ ${ }^{b}$ Trưòng Đại học Tân Trào \\ "Email:duchanh.xafs@gmail.com
}

\section{Thông tin bài viết}

Ngày nhận bài:

08/02/2020

Ngày duyệt đăng:

$10 / 3 / 2020$

\section{Tù khóa:}

Trường thực hành; trưòng công lâp; trường tu thuc; co sở giáo dục tụ chủ; truờng chất lượng cao.

\section{Tóm tắt}

Việc thành lập trường phổ thông có nhiều cấp học trong trường cao đẳng, đại học sư phạm và các trường đại học, cao đẳng có đào tạo giáo viên đang là một vấn đề thời sự hiện nay. Nghiên cứu này đã đưa ra một số khía cạnh mang tính pháp lý của việc thành lập trường phổ thông trong trường đại học, phân tích và so sánh cụ thể ba mô hình trường phổ thông trong các trường đại học thuộc khu vực Tây Bắc về tính pháp lý, sự thuận lợi và khó khăn của mỗi mô hình về công tác quản lý, về cơ sở vật chất, tài chính và đội ngũ cán bộ, giáo viên. Đồng thời nghiên cứu đã đưa ra một số khuyến nghị đối với việc hình thành cơ chế và hoạt động quản lý đối với mô hình trường phổ thông trong trường đại học.

\section{1. Đặt vấn đề}

Đã có nhiều trường đại học trong cả nước có trường phổ thông trực thuộc và phát huy các hoạt động hiệu quả, có uy tín trong ngành giáo dục như Trường Trung học cơ sở (THCS) - Trung học phổ thông (THPT) Nguyễn Tất Thành thuộc Trường Đại học Sư phạm (ĐHSP) Hà Nội; Trường THPT Chuyên thuộc Trường Đại học Khoa học Tự nhiên (KHTN), Đại học Quốc gia (ĐHQG) Hà Nội; Trường THPT Thái Nguyên thuộc Trường ĐHSP - Đại học Thái Nguyên; Trường Tiểu học $(\mathrm{TH})$, THCS, THPT Chu Văn An - Trường Đại học Tây Bắc; Trường TH, THCS, THPT - Đại học Hà Tĩnh,... gần đây là Trường phổ thông Thực hành trực thuộc Đại học Sài Gòn hay Trường THPT Chuyên Khoa học Xã hội và Nhân văn trực thuộc Trường Đại học Khoa học xã hội và Nhân văn, Đại học Quốc gia Hà Nội. Có những trường đại học hoàn toàn không liên quan gì đến khối ngành đào tạo giáo viên như Trường Đại học Lâm nghiệp Việt Nam, Trường Đại học Hàng hải, Hải Phòng cũng thành lập trường phổ thông, mỗi trường có một điều kiện ra đời khác nhau, hoạt động quản lý mang tính đặc thù khác nhau và có mức thu học phí rất khác nhau.

Một số phương tiện thông tin truyền thông có đề cập và bàn luận nhiều tới việc các trường đại học đua nhau mở trường phổ thông, không đúng với chức năng, nhiệm vụ được giao của trường đại học, không phải đầu tư ban đầu, lợi dụng cơ sở vật chất của trường đại học để mở trường phổ thông và thu học phí cao, tạo sự cạnh tranh không bình đẳng với các trường tư thục và các trường phổ thông công lập khác, .... Những băn khoăn này là hoàn toàn có cơ sở và các trường đại học phải phân định rõ được việc này và có trách nhiệm giải trình trước xã hội theo Luật giáo dục đại học và Điều lệ của trường đại học.

Để nhìn nhận và đánh giá xu hướng mở trường phổ thông trong các trường đại học, bài viết này phân tích trên góc độ của một trường đại học địa phương và chia sẻ kinh nghiệm cũng như hoạt động quản lý đối với mô hình trường học này, việc phân tích, so sánh sẽ thực hiện trên mô hình của 3 trường đại học thuộc vùng Tây Bắc gồm Đại học Tân Trào (Tuyên Quang), 
Đại học Hùng Vương (Phú Thọ) và Đại học Tây Bắc (Sơn La).

\section{Nội dung nghiên cứu}

\subsection{Co' sở pháp lý và nhu cầu thực tế của việc thành lập truòng phổ thông trục thuộc truòng đại học}

Các trường đại học, cao đẳng sư phạm hoặc các trường đại học, cao đẳng có đào tạo giáo viên đã vận dụng các văn bản của Bộ Giáo dục và Đào tạo (GD\&ĐT) để mở trường thực hành trong trường đại học và cao đẳng, cụ thể theo từng giai đoạn là (1) Quyết định số 31/1998/QĐ-BGD\&ĐT ngày 20/5/1998 của Bộ trưởng Bộ GD\&ĐT về việc ban hành Quy chế của trường thực hành sư phạm cho các trường sư phạm đào tạo giáo viên mầm non, tiểu học và trung học cơ sở; (2) Quyết định số 30/2001/QĐ-BGD\&ĐT ngày 30/7/2001 của Bộ trưởng Bộ GD\&ĐT về việc ban hành Quy chế trường thực hành sư phạm phục vụ công tác đào tạo giáo viên trung học phổ thông của các trường đại học sư phạm, khoa sư phạm trong các trường đại học khác. Gần đây nhất là (3) Thông tư số 16/2014/TT-BGDĐT ngày 16/5/2014 của Bộ trưởng Bộ GD\&ĐT về việc Ban hành quy chế hoạt động của trường thực hành sư phạm (Thông tư 16) [1]. Như vậy việc thành lập các trường mầm non, phổ thông trong các trường đại học sư phạm, các trường đại học có khoa sư phạm, đào tạo ngành sư phạm cơ bản là có cơ sở pháp lý từ Bộ chủ quản là Bộ GD\&ĐT về việc đào tạo khối ngành giáo viên.

Tuy nhiên, để thực sự quản lý tốt việc mở trường phổ thông trong trường đại học, các văn bản quy phạm pháp luật hiện tại vẫn còn chưa thực sự đầy đủ. Theo Điều 2 của Thông tư 16, trường mầm non, phổ thông thành lập do trường đại học đề xuất, trực thuộc trường đại học, ngoài ra không có quy định cụ thể và rõ ràng hơn về loại hình trường nên có nhiều mô hình khác nhau của các trường phổ thông trong trường đại học. Chỉ lấy 3 ví dụ đối với 3 trường phổ thông trực thuộc trường đại học trong cùng một khu vực thuộc các tỉnh vùng Tây Bắc: (1) Trường phổ thông Chu Văn An trực thuộc Đại học Tây Bắc, thành lập năm 2013, là trường phổ thông công lập, tự chủ một phần kinh phí chi thường xuyên (như trường phổ thông công lập bình thường khác bên ngoài); (2) Trường Phổ thông Tuyên Quang (TSE) trực thuộc Trường Đại học Tân Trào, thành lập tháng $01 / 2019$, là trường phổ thông công lập nhưng tự đảm bảo chi thường xuyên và chi đầu tư (là trường công lập nhưng hoạt động như tư thục); (3) Trường Phổ thông chất lượng cao (PTCLC) Hùng Vương, thành lập năm 2018, trực thuộc Trường
Đại học Hùng Vương (Phú Thọ) do một doanh nghiệp đứng ra liên kết với Đại học Hùng Vương thành lập và là loại hình trường tư thục. Rõ ràng chỉ với ba trường đại học trong cùng một khu vực, nhưng đã có 3 mô hình trường thực hành hoàn toàn khác nhau trực thuộc trường đại học.

Việc thành lập các trường phổ thông trong trường đại học còn xuất phát từ nhu cầu thực tế của hoạt động đào tạo đối với khối ngành sư phạm. Trong hệ thống giáo dục đại học, việc thực hành, thực tập là một học phần bắt buộc trong chương trình đào tạo, tùy theo ngành học, thời gian học mà các học phần này có thời lượng khác nhau, số tín chỉ khác nhau. Để chủ động và tạo điều kiện cho sinh viên được thực hành, thực tập thường xuyên, nhiều trường đại học đã mở các cơ sở thực hành, thực tập trong nhà trường, ví dụ phòng khám, bệnh viện, nhà thuốc cho khối ngành y-dược; các trung tâm thực hành, thực nghiệm, công ty, nhà xưởng, trang trại, vườn ươm cho các khối ngành kỹ thuật, nông lâm ngư nghiệp; khách sạn, nhà hàng cho khối ngành du lịch,... Việc thành lập trường mầm non, phổ thông để làm cơ sở thực hành trong trường đại học sư phạm hoặc đại học có khối ngành đào tạo giáo viên như các ngành đào tạo khác là cần thiết. Đây là xu hướng tốt và nên khuyến khích để sinh viên ra trường có thể đáp ứng ngay được với yêu cầu sử dụng lao động của xã hội và các trường học.

2.2. Phân tích một số mồ hình truờng phổ thông trục thuộc truò̀ng đại học thuộc khu vục Tây Bắc

2.2.1. Truờng Phổ thông Chu Văn An trục thuộc Truờng Đại học Tây Bắc, tỉnh Sơn La.

Theo Thông tư số 12/2011/TT-BGDĐT ngày 28/3/2011 (TT 12) và Thông tư số 41/2010/TTBGDĐT ngày 30/12/2010 của Bộ trưởng GD\&ĐT (TT 41) về việc ban hành Điều lệ trường THCS, THPT, trường phổ thông có nhiều cấp học [2] và Điều lệ trường Tiểu học [3] thì "Trường công lập do cơ quan nhà nước có thẩm quyền quyết định thành lập và Nhà nước trực tiếp quản lý. Nguồn đầu tư xây dựng cơ sở vật chất và kinh phí cho chi thường xuyên chủ yếu do ngân sách nhà nước bảo đảm". Trường Phổ thông Chu Văn An trực thuộc Trường Đại học Tây Bắc là loại hình trường theo mô hình này.

Thuận lợi của mô hình trường học như Trường Chu Văn An cho mọi hoạt động của nhà trường là đều có văn bản và quy định pháp lý rõ ràng, dễ thành lập, hoạt động hoàn toàn giống như một trường phổ thông công lập trực thuộc Sở GD\&ĐT, Phòng GD\&ĐT của địa phương. 
Tuy nhiên, sự khó khăn lại đến từ góc độ khác, đó là (1) do cơ sở vật chất của nhà trường đã có sẵn (và là trường trực thuộc Bộ GD\&ĐT) nên không được nhà nước (tỉnh Sơn $\mathrm{La}$ ) đầu tư, (2) đội ngũ giáo viên lấy từ giảng viên của Đại học Tây Bắc (vì gốc là trường sư phạm) và như vậy, nguồn chi thường xuyên đương nhiên sẽ lấy từ nguồn chi thường xuyên của trường đại học và cũng không được tỉnh Sơn $\mathrm{La}$ cấp, (3) vì là trường công lập nên Trường Phổ thông Chu Văn An chỉ được thu một phần học phí để bù đắp thêm cho chi thường xuyên, phần thu này rất thấp vì phải thực hiện theo Nghị quyết của HĐND tỉnh và theo quy định của Nghị định 86/2015/NĐ-CP ngày 02/10/2015 của Chính phủ về việc "Quy định về co' chế thu, quản lý học phi đối với so sở giáo dục thuộc hệ thống giáo dục quốc dân và chính sách miễn, giảm hoc phi, hố trợ chi phi hoc tập tù năm họ 2015-2016 đến năm hoc 2020-2021" [4], trước đó là Thông tư liên tịch số 14/TT-LB ngày 04/9/1993 của Liên bộ Giáo dục Đào tạo - Tài chính "Hướng dẫn thực hiện thu-chi học phí giáo dục phổ thông” theo Quyết định số 241/TTg ngày 24/5/1993 của Thủ tướng chính phủ "về việc thu và sử dụng hoc phí trong các trường hoc". Theo khảo sát, học phí của Trường Chu Văn An thu theo năm học 2019-2020 cao nhất là 52.000đ/tháng (468.000đ/cả năm), thấp nhất là 13.000 đ/tháng (117.000đ/cả năm) [6]. Với mức thu này, đương nhiên Trường Đại học Tây Bắc sẽ phải là đơn vị cấp bù hoàn toàn cho định mức chi thường xuyên của Trường Chu Văn An, nguồn kinh phí này lẽ ra phải được nhà nước cấp như các trường phổ thông bình thường khác, chưa kể đến việc cấp kinh phí đầu tư, bảo trì, bảo dưỡng cơ sở vật chất, trang thiết bị dạy học. Có thể nói, Trường Chu Văn An đã tạo thành một áp lực (nếu không nói là gánh nặng) cho Trường Đại học Tây Bắc bởi vì nguồn chi thường xuyên, đầu tư của giáo dục đại học phải trích ra một phần nuôi toàn bộ hoạt động của trường phổ thông trong khi việc tuyển sinh đại học gặp nhiều khó khăn. Trường Đại học Tây Bắc cố gắng duy trì hoạt động của Trường Chu Văn An là thực hiện nhiệm vụ chính trị tại địa phương và tất nhiên với trách nhiệm nghề nghiệp, các thầy cô giáo của Trường Chu Văn An hay của Đại học Tây Bắc vẫn phải mở lớp, giảng dạy nhiệt tình và chất lượng giáo dục cũng đã được khẳng định tại Sơn La.

2.2.2. Truờng Phổ thông chất lượng cao Hùng Vuơng trục thuộc Truờng Đại học Hùng Vuơng, tỉnh Phú Tho.
Năm 2018, Trường Phổ thông Chất lượng cao Hùng Vương (PTCLCHV) được thành lập trên cơ sở liên kết giữa Trường Đại học Hùng Vương và Công ty Cổ phần Tập đoàn Sông Hồng Thủ Đô [7] (Tập đoàn), như vậy, đây là trường phổ thông tư thục, hoạt động hoàn toàn tự chủ. Trong trường hợp này có sự không phân định rõ ràng về loại hình trường theo cấp quản lý, bởi vì: (1) Nếu trực thuộc Đại học Hùng Vương và có nhiệm vụ như trường thực hành thì Trường PTCLCHV phải là trường công lập, vì các đơn vị sự nghiệp công lập không được thành lập trường tư thục (theo Điều 4 của Thông tư 12 và Thông tư 41 của Bộ GD\&ĐT). Tuy nhiên, do Trường Đại học Hùng Vương liên kết với doanh nghiệp nên Trường PTCLCHV phải là loại hình trường tư thục. Như vậy, nếu Trường PTCLCHV trực thuộc Đại học Hùng Vương như thông báo tuyển sinh trên cổng thông tin điện tử của Đại học Hùng Vương [9] sẽ không đúng Điều lệ trường phổ thông và trường Tiểu học theo các Thông tư của Bộ GD\&ĐT. (2) Nếu Trường PTCLCHV là trường tư thục do Tập đoàn quản lý thì loại hình Trường PTCLCHV lại hoàn toàn hợp lý, bởi vì Trường Đại học Hùng Vương có quyền sử dụng quyền góp vốn bằng diện tích đất chưa sử dụng theo Điều 55, 57 của Luật quản lý, sử dụng tài sản công (Luật số 15/2017/QH14), có sẵn đội ngũ giáo viên (tiền thân của Trường Đại học Hùng Vương là trường cao đẳng sư phạm), tài chính do doanh nghiệp đầu tư. Nhưng theo website của Tập đoàn thì không tìm thấy chức năng của Tập đoàn được đầu tư hoạt động trong lĩnh vực giáo dục, đồng thời trên website của Tập đoàn cho tới hết tháng 11/2019 cũng không có chỉ dấu Trường PTCLCHV là một đơn vị trực thuộc, chỉ có một thông tin duy nhất về Trường PTCLCHV nhân ngày công bố thành lập [10]. Như vậy về danh nghĩa, Trường PTCLCHV là trường trực thuộc Đại học Hùng Vương hay trực thuộc Tập đoàn chưa được rõ ràng, phía nào cũng có vướng mắc về pháp lý. Tuy nhiên, trường phổ thông hình thành dưới sự bảo trợ về giáo dục của trường đại học, tài chính của doanh nghiệp, thu học phí cao sẽ khá thuận lợi trong mọi hoạt động.

\subsubsection{Truờng Phổ thông Tuyên Quang trục thuộc} Truòng Đại học Tân Trào, tỉnh Tuyên Quang.

Trong những năm qua, sự nghiệp giáo dục và đào tạo đã được tỉnh Tuyên Quang luôn xác định là một trong những nhiệm vụ quan trọng, cần phải có sự đột phá, đầu tư tập trung, toàn diện và hiệu quả theo quy hoạch phát triển kinh tế - xã hội của tỉnh và quy hoạch phát triển giáo dục và đào tạo đến năm 2020, định 
hướng đến năm 2025. Vì vậy, hệ thống giáo dục và đào tạo của tỉnh Tuyên Quang đã có đầy đủ từ hệ mầm non đến đại học, hệ thống giáo dục thường xuyên đã được mở rộng, cơ sở vật chất (CSVC) các trường học được nâng cấp, trang thiết bị dạy học ngày càng hiện đại, công tác bồi dưỡng, nâng cao chất lượng đội ngũ giáo viên thường xuyên được quan tâm. Về cơ bản, học sinh của tỉnh Tuyên Quang được đảm bảo về điều kiện tối thiểu để học tập văn hóa. Tuy nhiên, theo số liệu thống kê năm học 2017-2018 cho thấy, một số trường phổ thông, tiểu học, mầm non tại khu vực thành phố Tuyên Quang đang có sự quá tải, số học sinh/lớp vượt quá quy định của Bộ GD\&ĐT nhất là ở các lớp đầu cấp, các hoạt động bổ trợ như kĩ năng sống, giáo dục giới tính, vận dụng kiến thức để giải quyết vấn đề trong đời sống còn hạn chế, việc tổ chức học tập bán trú chưa được mở rộng, do cơ sở vật chất (CSVC), đội ngũ cán bộ giáo viên, người nuôi dưỡng thiếu, trong khi đó nhu cầu học bán trú của học sinh là rất cao. Để giải quyết vấn đề này, việc xã hội hóa và tổ chức các trường tư thục hoặc các trường công lập nhưng tự đảm bảo chi thường xuyên là cần thiết vừa giảm áp lực về trường lớp học, vừa giảm gánh nặng về ngân sách cho nhà nước. Trên cơ sở thực tế, năm 2018 Trường Đại học Tân Trào đã xây dựng Đề án thành lập trường phổ thông và tháng 01/2019, Trường Phổ thông Tuyên Quang (TSE) đã được thành lập trực thuộc Trường Đại học Tân Trào, là trường phổ thông liên cấp, công lập, hoạt động theo mô hình tự chủ về chi thường xuyên và chi đầu tư [8].

Mô hình của Trường Phổ thông Tuyên Quang (TSE) trực thuộc Trường Đại học Tân Trào khác với các mô hình của Đại học Tây Bắc và Đại học Hùng Vương. TSE là trường phổ thông công lập nên trực thuộc Trường Đại học Tân Trào là đúng quy định bởi Trường Đại học Tân Trào có khoa đào tạo giáo viên, hình thành trên cơ sở của Trường Cao đẳng Sư phạm Tuyên Quang trước đây. Hoạt động theo mô hình tự chủ hoàn toàn nên (1) TSE không sử dụng biên chế nhà nước như vậy sẽ không làm tăng biên chế sự nghiệp của tỉnh là phù hợp với chủ trương của Đảng và Nhà nước về tinh giảm biên chế (Nghị quyết số 39NQ/TW ngày 17/4/2015 của Ban chấp hành Trung ương về tinh giảm biên chế và cơ cấu lại đội ngũ cán bộ, công chức, viên chức; Nghị định số 113/2018/NĐCP ngày 31/8/2018 của Chính phủ về Sứa đổi, bổ sung một số điều của Nghi định số 108/2014/ND-CP ngày 20/11/2014 của Chính phủ về chính sách tinh giảm biên chế). (2) Nhà nước không mất kinh phí cho chi thường xuyên và đầu tư CSVC, trang thiết bị, giảm áp lực chi cho tỉnh nhưng vẫn tạo thêm được nơi học tập cho học sinh giảm áp lực trường lớp học ở khu vực thành phố Tuyên Quang là phù hợp với chủ trương xã hội hóa giáo dục theo Nghị quyết số 05/2005/NQ-CP ngày 18/4/2005 của Chính phủ về Đẩy mạn xã hội hóa các hoạt động giáo duc, y tế, văn hóa và thể dục thể thao (Nghị quyết 05) [5]. (3) Đề án thành lập trường được xây dựng theo mô hình giáo dục chất lượng cao theo bốn tiêu chí chủ yếu: về chương trình giáo dục; về đội ngũ quản lý, giáo viên; về CSVC, trang thiết bị và về các dịch vụ đáp ứng. Mức học phí bước đầu được xác định trên cơ sở tính toán thu đủ chi thường xuyên, chưa có kinh phí chi đầu tư.

\subsection{Thảo luận}

Việc thành lập các trường phổ thông trong trường đại học sư phạm hoặc đại học có đào tạo giáo viên là nhu cầu thực tiễn có thật và cấp thiết. Tuy nhiên cũng cần phân tích và làm rõ hơn hoạt động của các mô hình trường học này về thế nào là chất lượng cao (CLC), về công tác quản lý, đội ngũ giáo viên, CSVC, tài chính để minh bạch các hoạt động này giữa trường đại học và trường phổ thông trong trường đại học.

\subsubsection{Mô hình trường chất luợng cao}

Hiện tại, khái niệm trường CLC có đề cập đến trong Nghị định số 86/2015/NĐ-CP ngày 02/10/2015 của Chính phủ, tại Điều 4. Khung học phí đối với giáo dục mầm non và phổ thông, điểm 4 có quy định "Các cơ sở giáo duc mầm non, phổ thông công lập chất luơong cao chủ động xây dựng mưc học phí tuơng xưng để trang trải chi phí đào tạo, trình Ủy ban nhân dân cấp tỉnh phê duyệt và thực hiện Quy chế công khai do Bộ Giáo duc và Đào tạo quy định". Tuy nhiên, Bộ GD\&ĐT cũng chưa có thông tư hướng dẫn chung cụ thể thế nào là trường CLC để áp dụng, một số ít tỉnh, thành phố đã xây dựng và ban hành quy định trường CLC cho riêng địa phương mình để thực hiện. Vì vậy, việc triển khai hướng dẫn xây dựng các tiêu chí để xác định trường CLC là hết sức cần thiết để tạo nên một quy chuẩn chung, tránh mỗi địa phương đưa ra một tiêu chí khác nhau. Theo tra cứu, tỉnh Phú Thọ chưa ban hành quy chuẩn về trường phổ thông $\mathrm{CLC}$, vì vậy việc đặt tên trường có cụm từ CLC là chưa có cơ sở về mặt pháp lý, tuy nhiên là trường tư thục nên mức thu học phí do nhà trường tự xác định [11]. Tỉnh Tuyên Quang cũng chưa ban hành quy định về tiêu chí của trường CLC, vì thế TSE không có cụm từ CLC trong tên gọi để đảm bảo về tính pháp lý, nhưng Đề án thành lập trường đã đưa ra các tiêu chí giáo dục, dịch vụ đều gắn với khái niệm $\mathrm{CLC}$ trên cơ sở các yếu tố về (1) 
đội ngũ quản lý, giáo viên; (2) chương trình giảng dạy; (3) cơ sở vật chất, trang thiết bị dạy học và (4) các dịch vụ đáp ứng. Tất cả các yếu tố này đều được công khai theo đúng quy định để xã hội có thể theo dõi và kiểm chứng.

\subsubsection{Sụ thống nhất trong công tác quản lý}

Trường phổ thông trong trường đại học có hai (2) cấp quản lý, trường đại học quản lý hành chính nhà nước trực tiếp, Sở GD\&ĐT quản lý về mặt chuyên môn đối với trường có cấp cao nhất là $\mathrm{THPT}$ và Phòng GDĐT quản lý chuyên môn đối với trường có cấp từ THCS trở xuống. Con dấu của trường có vành ngoài là Sở GDĐT hoặc Phòng GDĐT, bên trong là tên trường.

Theo quy định của Điều lệ, Sở GDĐT hoặc Phòng GDĐT theo phân cấp sẽ bổ nhiệm Hiệu trưởng (và Phó Hiệu trưởng) đối với các trường công lập và công nhận Hiệu trưởng đối với trường tư thục. Điều lệ quy định khá rõ nhưng thực tế lại có những tình huống mà Điều lệ chưa thể tính hết được do sự đa dạng và phát triển nhanh của xã hội. Đối với Trường Đại học Tây Bắc, Hiệu trưởng của Trường Chu Văn An được Sở GDĐT Sơn La bổ nhiệm và là giảng viên trong biên chế của Đại học Tây Bắc; Hiệu trưởng Trường phổ thông CLCHV (trường tư thục), không phải là giảng viên của Đại học Hùng Vương, được Sở GDĐT Phú Thọ công nhận, cả hai trường hợp là đúng quy định và không có vướng mắc, dĩ nhiên phải có sự đồng thuận, giới thiệu của Hiệu trưởng các Trường Đại học Tây Bắc, Hùng Vương hoặc Hội đồng trường của các trường phổ thông và được thực hiện theo quy trình. Trường Phổ thông Tuyên Quang (TSE) lại hoàn toàn khác, xét theo khía cạnh là trường tự chủ hoàn toàn về chi thường xuyên và đầu tư, nghĩa là TSE không có biên chế, nếu Sở GDĐT bổ nhiệm Hiệu trưởng theo Điều lệ thì phải bổ nhiệm người trong biên chế nhà nước, TSE không có nhân sự trong biên chế để bổ nhiệm. Hiện tại, Hiệu trưởng, Phó Hiệu trưởng TSE do Hiệu trưởng Đại học giao giảng viên của đại học kiêm nhiệm và bổ nhiệm. Tuy chưa thật sự đúng với Điều lệ nhưng hiện tại các đơn vị tham mưu của tỉnh Tuyên Quang chưa thể có giải pháp phù hợp hơn Việc bổ nhiệm áp dụng tương tự như Hiệu trưởng của các trường đại học địa phương, Bộ GDĐT quản lý nhà nước về mặt chuyên môn nhưng không bổ nhiệm Hiệu trưởng, hơn nữa TSE xét cho cùng cũng chỉ là một đơn vị trực thuộc Đại học Tân Trào như các đơn vị phòng, khoa, trung tâm khác. Đây là một vướng mắc nếu Điều lệ trường tiểu học, phổ thông không sửa đổi, bổ sung thì trong tương lai sẽ có thêm các loại hình hoạt động giáo dục khác thuộc các đơn vị sự nghiệp công lập nhưng hoạt động tự chủ sẽ bị vướng trong phân cấp quản lý.

\subsubsection{Thuận lợi và khó khăn đối với đội ngũ giáo viên}

Những lợi thế về đội ngũ giáo viên của các trường phổ thông trong trường đại học sư phạm và đại học có đào tạo giáo viên (nhưng phải có gốc từ các trường sư phạm) đó là có sẵn đội ngũ giáo viên có trình độ cao, có kinh nghiệm sư phạm, có đủ tất cả các giáo viên của các môn học đặc thù như tâm lý, âm nhạc, mỹ thuật, thể dục thể thao và các môn chung khác như tin học, ngoại ngữ.

Tuy nhiên, sẽ có hạn chế rất lớn mà các trường phải vượt qua, cụ thể:

(1) Đối với chuyên môn: Đối tượng giảng dạy, quản lý chủ yếu và quen thuộc của giảng viên là sinh viên, đây là đối tượng người học có tính tự học, tự quản cao, việc giảng dạy, quản lý lớp học không đòi hỏi người giáo viên phải quá chi tiết, sát sao, nên hầu hết các giảng viên đại học rất ngại và rất khó tiếp cận được với chương trình, soạn giảng cũng như phương pháp giảng dạy và quản lý đối với học sinh phổ thông, đặc biệt là đối với khối tiểu học thì việc giáo dục, chăm sóc trẻ đòi hỏi người giáo viên phải có $100 \%$ thời gian dành cho học sinh, phải hiểu biết tâm, sinh lý học sinh và biết chia sẻ (vất vả hơn nhiều so với quản lý sinh viên), hơn nữa giảng dạy các lớp tiểu học đòi hỏi giáo viên phải dạy tất cả các môn học, nhưng đội ngũ giảng viên Khoa Tiểu học của các trường đại học, cao đẳng chỉ chủ yếu giảng dạy một trong 2 môn toán hoặc văn, vì vậy rất khó hoặc có thể nói không thể tiếp cận ngay với hệ thống giáo dục tiểu học (cho dù các thầy, cô đào tạo và cho ra trường rất nhiều giáo viên tiểu học).

(2) Đối với việc giao giảng viên đại học để dạy phổ thông: Thứ nhất, về mặt tâm lý, giảng viên đại học rất ngại và không muốn chuyển xuống dạy phổ thông (trừ trường hợp giảng viên thiếu giờ hoặc các bộ môn đặc thù phải giảng dạy theo phân công), vì sẽ vất vả hơn nhiều so với dạy đại học, cao đẳng. Thứ hai, chế độ, định mức lao động tính toán thế nào để không bị hiểu là sử dụng giảng viên hưởng lương của đại học để giảng dạy cho phổ thông. Thứ ba, việc quản lý chuyên môn của giáo viên phổ thông là giảng viên đại học như thế nào, trường phổ thông quản lý thế nào, khoa quản lý thế nào để hoạt động chuyên môn hài hòa và đúng quy định, quy chế của giáo dục phổ thông. 
Đối với TSE và Trường PTCLCHV thì việc giải quyết vấn đề giáo viên khá dễ dàng do cơ chế tự chủ và nguồn học phí có thể hợp đồng với các giáo viên bên ngoài, giảng viên đại học chỉ hỗ trợ trên góc độ cố vấn. Nhưng đối với Trường Phổ thông Chu Văn $\mathrm{An}$ thì việc hợp đồng thêm giáo viên giảng dạy sẽ là khó khăn vì Trường Đại học Tây Bắc sẽ phải mất thêm chi phí, trong khi nguồn thu học phí từ phổ thông rất thấp.

\subsubsection{Phân định về cơ sở vật chất, tài chính}

Nếu trường phổ thông trực thuộc đại học được xây dựng riêng một khu và hoạt động độc lập với đại học thì chắc sẽ không có nhiều ý kiến xã hội về việc lợi dụng cơ sở vật chất sẵn có của đại học (cả đội ngũ giảng viên) để mở trường, do không phải đầu tư nên đã tạo ra sự cạnh tranh không lành mạnh với các trường tư thục. Đây là một lo ngại có cơ sở, tuy nhiên, các trường đại học mở ra trường học ngoài tác dụng làm cơ sở thực hành, thực tập cho sinh viên còn là một hoạt động thiết thực nhằm giải tỏa áp lực cho địa phương khi số học sinh tăng lên theo sự gia tăng dân số, nhà nước tiết kiệm được tài chính chi trả con người và đầu tư xây dựng trường lớp, giảm áp lực chi của địa phương. Việc sử dụng cơ sở vật chất của trường đại học cũng là một hình thức tiết kiệm, tăng hiệu quả sử dụng cơ sở vật chất, trang thiết bị, đồng thời là một hoạt động làm tăng công tác xã hội hóa giáo dục, phục vụ cộng đồng, thực hiện sứ mạng, tầm nhìn của các trường đại học. Vấn đề là xử lý việc sử dụng cơ sở vật chất, tài chính giữa trường phổ thông và trường đại học như thế nào là việc làm của từng trường để minh bạch trước xã hội và người học. Riêng với TSE, tất cả hoạt động phục vụ công tác dạy và học của nhà trường có liên quan đến Đại học Tân Trào đều được trích chi trả trên cơ sở hợp lý. Ngược lại TSE cũng có nguồn thu từ đại học, ví dụ Đại học Tân Trào phải chi trả cho TSE kinh phí cho sinh viên thực tập dưới sự hướng dẫn của giáo viên TSE. Quy chế chi tiêu nội bộ của TSE cũng quy định rõ mức chi, đối tượng chi cho giảng viên của Đại học Tân Trào tham gia vào các hoạt động trường phổ thông để tránh việc hưởng lương của đại học nhưng làm việc cho trường phổ thông.

\section{Kết luận và khuyến nghị}

Việc thành lập trường tiểu học, trường phổ thông, trường phổ thông liên cấp trong trường đại học là một hoạt động đã được thực hiện từ nhiều năm trước đây, tuy nhiên thời gian này, số trường thành lập có xu hướng gia tăng kể cả đối với các trường đại học không có nhiều liên quan tới khối ngành đào tạo giáo viên đã đem lại nhiều băn khoăn cho xã hội. Nếu xét trên góc độ tích cực, đây là một hình thức xã hội hóa, phục vụ cộng đồng, đặc biệt là làm giảm áp lực về trường lớp ở các thành phố lớn, những khu vực trung tâm của các tỉnh điều kiện trong khi nhà nước chưa có đủ nguồn lực về con người, về tài chính và cơ sở vật chất để đáp ứng, đồng thời cũng tạo nên một sự cạnh tranh, cơ hội lựa chọn cho học sinh để không tạo nên sự sơ cứng trong giáo dục phổ thông theo khuôn mẫu, ngược với xu hướng toàn cầu hóa và hội nhập quốc tế trong thời kỳ cuộc cách mạng công nghiệp lần thứ Tư đang diễn ra mạnh mẽ trên toàn thế giới

Đối với các trường đại học, trước khi xây dựng đề án mở trường cần phải cân nhắc về mô hình trường, về góc độ quản lý, về đội ngũ để đảm bảo chất lượng giáo dục phổ thông, cân nhắc mức thu phù hợp với điều kiện kinh tế-xã hội của địa phương, phù hợp với những dịch vụ giáo dục mà học sinh được hưởng thụ, không nên coi việc mở trường chủ yếu để giải quyết công ăn việc làm cho giảng viên đại học trong giai đoạn khó khăn về công tác tuyển sinh, đào tạo hay đơn giản là muốn tăng thêm nguồn thu cho nhà trường. Nếu như vậy, mục tiêu của Thông tư 16 hay công tác xã hội hóa giáo dục theo Nghị quyết 05 sẽ không đạt được.

Đối với Bộ GD\&ĐT cần ban hành các văn bản hướng dẫn cụ thể về các mô hình trường phổ thông, loại hình trường phổ thông, văn bản ban hành về các tiêu chuẩn, quy chuẩn về trường phổ thông $\mathrm{CLC}$, cũng như các văn bản phân cấp quản lý theo hướng mở, để tạo điều kiện cho giáo dục đào tạo phát triển.

\section{Tài liệu tham khảo}

1. Quy chế hoạt động của trường thực hành sư phạm, Thông tư số 16/2014/TT-BGDĐTcủa Bộ trưởng Bộ GDĐT, (2014).

2. Điều lệ trường THCS, THPT, trường phổ thông có nhiều cấp học, Thông tư số 12/2011/TT-BGDĐT, (2011).

3. Điều lệ trường Tiểu học, Thông tư số 41/2010/TT-BGDĐT, (2010).

4. Quy định về cơ chế thu, quản lý học phí đối với sơ sở giáo dục thuộc hệ thống giáo dục quốc dân và chính sách miễn, giảm học phí, hỗ trợ chi phí học tập ..., Nghị định 86/2015/NĐ-CP của Chính phủ, (2015).

5. Đẩy mạnh xã hội hóa các hoạt động giáo dục, y tế, văn hóa và thể dục thể thao, Nghị quyết số 05/2005/NQ-CP của Chính phủ, (2005). 
6. http://chuvanantaybac.edu.vn/tin-tuc/tin-tuc-sukien/thu-hoc-phi-va-bao-hiem-y-te-nam-hoc-20192020-tai-truong-th.html.

7. http://hvschool.edu.vn/content-270/gioi-thieuve-truong-ptclc-hung-vuong/

8. http://tse.daihoctantrao.edu.vn/gioi-thieuchung.html

9. http://www.hvu.edu.vn/tin-tuc/thong-tin-tuyensinh-truong-pho-thong-chat-luong-cao-hungvuong.hvu
10. http://songhong-thudo.com/d103/ron-rang-lecong-bo-quyet-dinh-thanh-lap-truong-pho-thong-chatluong-cao-hung-vuong-va-khai-giang-nam-hoc-20182019.html

11. https://doisongvietnam.vn/truong-pho-thongchat-luong-cao-hung-vuong-tien-tram-hau-tau-ngangnhien-tuyen-sinh-trai-phep-45474-3.html

\title{
Establishing a multi-level practical school in universities - exchange from reality of Tan Trao University, Tuyen Quang province
}

\author{
Nguyen Duc Hanh, Nguyen Ba Duc
}

\section{Article info}

Recieved:

08/02/2020

Accepted:

$10 / 3 / 2020$

Keywords:

practical school; public school; private school; autonomous educational institutions; high quality school.

\begin{abstract}
Establishment of multi-level practical school under Pedagogical University and Pedagogical College or in universitie and colleges with teacher training control not only a current affair issue and but also one of the new options for a number of universities. This article has researched and given a number of legal aspects of establishing a school in a university, analyzed and compared specifically three school models in universities in the Northwest area for the legality, the advantages and disadvantages of each model of management, facilities, financial, staffs and teachers. At the same time, the study has made a number of recommendations for the formation mechanism and management model for schools in the university.
\end{abstract}

